BRAVZULIAN JOURNAL

OF MEDICAL AND BIOLOGICAL RESH.ARCH

www.bjournal.com.br
ISSN 0100-879X

Volume 44 (7) 606-728 July 2011

BIOMEDICAL SCIENCES

AND

CLINICAL INVESTIGATION

Braz J Med Biol Res, July 2011, Volume 44(7) 725-728

doi: 10.1590/S0100-879X2011007500076

Amniotic fluid amino acid levels in non-immune hydrops fetalis: a case-control study

M. Erdemoğlu, U. Kuyumcuoglu, A.I. Guzel, Y. Celik and E. Kale

The Brazilian Journal of Medical and Biological Research is partially financed by

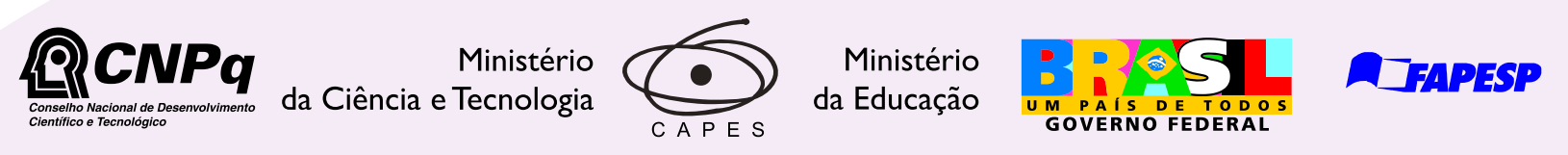

Institutional Sponsors
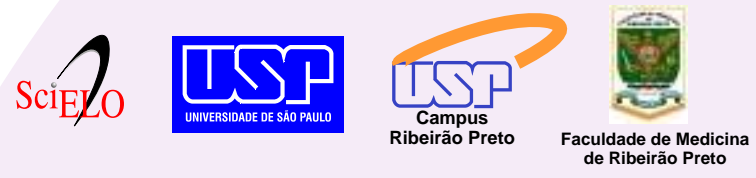
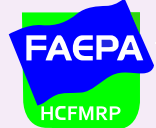

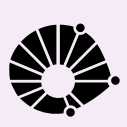

Ф SHIMADZU

GE Healthcare
Hotsite of proteomics metabolomics developped by:

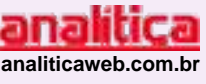

Thermo SCIENTIFIC 


\title{
Amniotic fluid amino acid levels in non-immune hydrops fetalis: a case-control study
}

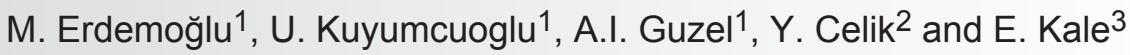

${ }^{1}$ Department of Obstetrics and Gynecology, ${ }^{2}$ Department of Biostatistics and Medical Informatics, ${ }^{3}$ Department of Clinical Biochemistry, Faculty of Medicine, Dicle University, Diyarbakir, Turkey

\begin{abstract}
In a prospective case-control study, we compared the amniotic fluid amino acid levels in non-immune hydrops fetalis (NIHF) and normal fetuses. Eighty fetuses underwent amniocentesis for different reasons at the prenatal diagnosis unit of the Department of Obstetrics and Gynecology, Faculty of Medicine, Dicle University. Forty of these fetuses were diagnosed with NIHF. The study included 40 women each in the NIHF (mean age: $27.69 \pm 4.56$ years) and control $(27.52 \pm 5.49$ years) groups, who had abnormal double- or triple-screening test values with normal fetuses with gestational ages of $23.26 \pm 1.98$ and $23.68 \pm 1.49$ weeks at the time of sample collection, respectively. Amniotic fluid amino acid concentrations (intra-assay variation: $2.26-7.85 \%$; interassay variation: 3.45-8.22\%) were measured using EZ:faast kits (EZ:faast GC/FID free (physiological) amino acid kit; Phenomenex, USA) by gas chromatography. The standard for quantitation was a mixture of free amino acids from Phenomenex. The levels of 21 amino acids were measured. The mean phosphoserine and serine levels were significantly lower in the NIHF group, while the taurine, $\alpha$-aminoadipic acid (aaa), glycine, cysteine, $\mathrm{NH}_{4}$, and arginine (Arg) levels were significantly higher compared to control. Significant risk variables for the NIHF group and odds coefficients were obtained using a binary logistic regression method. The respective odds ratios and $95 \%$ confidence intervals for the risk variables phosphoserine, taurine, aaa, Arg, and $\mathrm{NH}_{4}$ were 3.31 (1.84-5.97), 2.45 (1.56-3.86), 1.78 (1.18-2.68), 2.18 (1.56-3.04), and 2.41 (1.66-3.49), respectively. The significant difference between NIHF and control fetuses suggests that the amniotic fluid levels of some amino acids may be useful for the diagnosis of NIHF.
\end{abstract}

Key words: Non-immune hydrops fetalis; Amniotic fluid; Amino acid levels

\section{Introduction}

Hydrops fetalis is a severe condition of the fetus causing the accumulation of excess fluid in more than one body compartment. This fluid is usually present in body cavities, such as subcutaneous tissues, lungs, abdominal cavity, and pericardial cavity (1). In 1943, Potter described non-immune hydrops fetalis (NIHF) as generalized edema of the fetus not associated with erythroblastosis. The incidence of NIHF is 1 in 2500-3500 newborns. There are many causes of NIHF, but the etiology is most commonly idiopathic $(50 \%)(2,3)$. No specific, successful management strategy has been established for NIHF; thus, the mortality rate remains high (4). Czernik et al. (5) evaluated the diagnostic spectrum and its relationship with fetal mortality in NIHF and found no association between diagnosis and mortality. However, low gestational age (<34 weeks), low 5-min Apgar scores $(<4)$, and heart failure were significantly associated with fetal mortality. Due to fetal heart failure and circulatory insufficiency, tissue hypoxia occurs in NIHF and vascular endothelial cell injury results in increased capillary permeability (6). Bellini et al. (7) reported that liver and cardiac failure, volume overload, and lymphatic disorders lead to low oncotic pressure, high central venous pressure, and decreased lymphatic flow, resulting in NIHF. The altered capillary permeability may lead to amino acid leakage into the amniotic fluid.

We designed this prospective, case-control study to evaluate amniotic amino acid levels in NIHF and to determine whether these levels could be criteria for the diagnosis of NIHF.

\section{Material and Methods}

A prospective, case-control study was performed at the perinatal diagnosis unit of the Department of Obstetrics and Gynecology, Faculty of Medicine, Dicle University, from January 2009 to January 2010.

Correspondence: A.I. Guzel, Mega Center Karsisi, Polis Loj Sok, Murat 6, Apto. 25, Diyarbakir, Turkey. Fax: +90-412-611-5114.

E-mail: alijnk@hotmail.com

Received June 17, 2010. Accepted June 6, 2011. Available online June 17, 2011. Published July 25, 2011. 
The study was approved by the Institutional Ethics Committee and written informed consent was obtained from all patients.

Patients with immune hydrops fetalis (Rhesus (Rh)negative mothers and Rh-positive fathers) were excluded. All fetuses were examined by an experienced obstetrician. Before amniocentesis, a detailed ultrasound examination was performed, including the observation of the presence of generalized skin thickening $>5 \mathrm{~mm}$ and at least two of the following features: ascites, pleural effusion, pericardial effusion, or placental enlargement. Patients with NIHF fetuses were also evaluated for maternal infections, such as Toxoplasma gondii, rubella virus, cytomegalovirus, and herpes simplex virus.

Eighty cases were included. Amniotic fluid was collected by transabdominal amniocentesis under ultrasonographic guidance (Volusun 730 PRO 4-D ultrasound device; GE Healthcare, USA). Amniotic fluid (2-mL tubes) was obtained from NIHF and normal fetuses. The normal fetuses underwent amniocentesis when the double- or triple-screening tests were abnormal but had no structural abnormality on ultrasound examination.

All samples were centrifuged immediately at $3000 \mathrm{~g}$ for $10 \mathrm{~min}$ and stored at $-20^{\circ} \mathrm{C}$ until assayed. The levels of free amino acids (intra-assay variation: $2.26-7.85 \%$; interassay variation: $3.45-8.22 \%$ ), essential amino acids (histidine, leucine, lysine, isoleucine, phenylalanine, threonine, tryptophan, and valine), non-essential amino acids (alanine, asparagine, aspartic acid, serine, cysteine, glutamic acid, glutamine, glycine, ornithine, and proline), phosphoserine, a-aminoadipic acid (aaa), and $\mathrm{NH}_{4}$ were measured in amniotic fluid samples using EZ:faast kits (EZ:faast GC/FID free (physiological) amino acid kit; Phenomenex, USA) by gas chromatography (Focus GCAI 3000 Thermo Finnegan analyzer, Italy; injection: split $1: 15$ at $250^{\circ} \mathrm{C}, 2.5 \mu$; carrier gas: helium $1.5 \mathrm{~mL} / \mathrm{min}(60 \mathrm{kPa})$ at $110^{\circ} \mathrm{C}$; pressure rise: $6 \mathrm{kPa} / \mathrm{min}$; oven program: $30^{\circ} \mathrm{C} / \mathrm{min}$ from 110 to $320^{\circ} \mathrm{C}$, kept at $320^{\circ} \mathrm{C}$ for $1 \mathrm{~min}$; detector: FID at $320^{\circ} \mathrm{C}$; intra-assay variation: $2.4 \%$; interassay variation: $3.2 \%$ ). The standard for quantitation was a mixture of free amino acids from Phenomenex. Amino acid analyses were carried out in duplicate or triplicate.

\section{Statistical analyses}

The mean and standard deviation (SD) were calculated for continuous variables. The normality of the variables was analyzed using the Kolmogorov-Smirnov test. Chi-square and independent sample $t$-tests were used to evaluate associations between the categorical and continuous variables. Significant risk variables for the NIHF group and odds coefficients were determined using a binary logistic regression method. All variables were included in the backward stepwise procedure. Two-sided $P$ values were considered to be statistically significant at $P<0.05$. Statistical analyses were performed using the SPSS software (ver. 15.0 for Windows; SPSS, USA).

The sample size was determined according to the results of the central limit theorem, which indicated that we needed at least 30 individuals in each subgroup (8). Thus, we included 40 individuals each in the study and control groups. The statistical power $(87 \%)$ of the study was calculated using the Power and Precision ${ }^{\mathrm{TM}}$ software, release 4.0 May 3, 2010.

\section{Results}

The demographic and clinical characteristics of the cases are shown in Table 1. The NIHF and control groups had a median gestational age of $23.68 \pm 1.49$ and $23.26 \pm$ 1.98 weeks at the time of sample collection, respectively. Mean maternal age was $27.69 \pm 4.56$ and $27.52 \pm 5.49$ years for the NIHF and control groups, respectively. The majority of women in both groups were multiparous.

All fetuses were evaluated by ultrasonography (Volusun 730 PRO 4-D ultrasound device). NIHF was assessed as accumulation of excess fluid in one or more body cavities, including the subcutaneous tissues, lungs, abdominal cavity, and pericardial cavity. Chromosome analysis was normal for both groups. Control fetuses showed no structural abnormality on ultrasonographic evaluation. The groups are compared in Table 1. There was no significant difference between groups in terms of age, gestational age, or gravidity.

Before amniocentesis, we evaluated the NIHF fetuses for etiology, but found no etiological cause. Thus, we deter-

Table 1. Demographic and clinical characteristics of the mothers of fetuses with nonimmune hydrops fetalis and controls.

\begin{tabular}{lccc}
\hline & $\begin{array}{c}\text { Non-immune hydrops } \\
\text { fetalis }(\mathrm{N}=40)\end{array}$ & $\begin{array}{c}\text { Control group } \\
(\mathrm{N}=40)\end{array}$ & Test values \\
\hline Gravidity $\leq 4$ & $24(60 \%)$ & $31(77.5 \%)$ & $\mathrm{X}^{2}=2.090 ; \mathrm{P}=0.148$ \\
Age & $27.69 \pm 4.56$ & $27.52 \pm 5.49$ & $\mathrm{~T}=0.109 ; \mathrm{P}=0.914$ \\
Gestational weeks & $23.26 \pm 1.98$ & $23.68 \pm 1.49$ & $\mathrm{~T}=-0.768 ; \mathrm{P}=0.447$ \\
\hline
\end{tabular}

Data are reported as means \pm SD or as number with percent in parentheses. Statistical analysis was carried out by the chi-square test and the Student $t$-test. 
mined the amniotic fluid amino acid concentrations and the mean values for the NIHF and control groups are given in Table 2. The mean phosphoserine and serine levels were significantly lower in the NIHF group ( $P<0.05)$, while the taurine, aaa, glycine, cysteine, $\mathrm{NH}_{4}$, and arginine levels were significantly higher compared to control $(P<0.05)$.

Table 3 summarizes the outcomes of the logistic regression models. According to the models, the phosphoserine, taurine, $\mathrm{NH}_{4}$, arginine, and aaa levels were statistically significant risk factors. The odds ratios and $95 \% \mathrm{Cl}$ of the risk variables phosphoserine, taurine, aaa, arginine, and $\mathrm{NH}_{4}$ were 3.31 (1.84-5.97), 2.45 (1.56-3.86), 1.78 (1.18-2.68), 2.18 (1.56-3.04), and 2.41 (1.66-3.49), respectively.

Based on the results obtained with the Power and Precision software, the statistical power of the study was found to be as approximately $87 \%$.

\section{Discussion}

In this study, we compared the amniotic fluid amino acid levels of NIHF and normal fetuses. The amino acid levels were higher in the study group than in the control group. lijima and Ohzehi (6) reported that, due to fetal heart failure and circulatory insufficiency, tissue hypoxia occurs in NIHF and vascular endothelial cell injury results in increased capillary permeability. Bellini et al. (7) also reported that disordered capillary permeability may lead to increased levels of amniotic fluid amino acid concentrations. We believe that this increased capillary permeability and excess edema results in the elevated amniotic fluid amino acid concentrations. The statistical power of this study was approximately $87 \%$, indicating that the results are reliable.

In decreasing order of importance, the etiology of NIHF includes vascular $(20 \%)$, chromosomal $(16 \%)$, hematological $(10 \%)$, and placental $(8 \%)$ causes, as well as an idiopathic cause. Maternal causes are rare and are mostly infection or diabetes mellitus (DM) $(9,10)$. Mascaretti et al. (11) studied the characteristics of newborns with NIHF and reported that $38 \%$ of the fetuses with hydrops fetalis in their study were in the idiopathic etiology group. In contrast to the report by Mascaretti et al. (11), most of our fetuses with NIHF were in the idiopathic etiology group. Eleven of our fetuses had congenital heart anomalies, one mother had DM, and another had toxoplasmosis.

Queenan (12) reported that, in the second trimester, the main source of amniotic fluid amino acids is fetal and these amino acids enter the amniotic cavity via the fetal skin, kidneys, lungs, and digestive tract. Small amino acid molecules, such as taurine, threonine, glutamic acid, proline, alanine, valine, leucine, and lysine, were found at higher concentrations in first-trimester amniotic fluid

Table 2. Comparison of amniotic fluid amino acid levels between groups.

\begin{tabular}{lcc}
\hline & $\begin{array}{c}\text { Non-immune hydrops } \\
\text { fetalis }(\mathrm{N}=40)\end{array}$ & $\begin{array}{c}\text { Control group } \\
(\mathrm{N}=40)\end{array}$ \\
\hline Alanine & $357.16 \pm 167.19$ & $386.01 \pm 93.40$ \\
Arginine & $\mathbf{4 8 . 3 0} \pm \mathbf{7 . 7 8}$ & $\mathbf{8 4 . 1 7} \pm \mathbf{1 0 . 3 8 ^ { * }}$ \\
Asparagine & $55.87 \pm 49.56$ & $109.50 \pm 125.89$ \\
Aspartic acid & $17.74 \pm 21.95$ & $14.30 \pm 16.16$ \\
a-amino adipic acid & $\mathbf{2 0 . 8 8} \pm \mathbf{2 4 . 6 7}$ & $\mathbf{8 . 2 4} \pm \mathbf{7 . 0 0 ^ { * }}$ \\
NH $_{\mathbf{4}}$ & $\mathbf{4 7 1 . 8 3} \pm \mathbf{2 5 8 . 1 4}$ & $\mathbf{2 4 7 . 2 3} \pm \mathbf{9 2 . 7 6 ^ { * }}$ \\
Cysteine & $\mathbf{2 9 . 4 9} \pm \mathbf{1 9 . 6 0}$ & $\mathbf{1 7 . 8 4} \pm \mathbf{1 3 . 9 2 ^ { * }}$ \\
Histidine & $136.65 \pm 5.26$ & $128.05 \pm 39.58$ \\
Isoleucine & $74.57 \pm 29.52$ & $73.15 \pm 35.95$ \\
Glutamic acid & $55.80 \pm 32.93$ & $50.77 \pm 21.67$ \\
Glutamine & $138.45 \pm 137.87$ & $150.59 \pm 150.57$ \\
Glycine & $\mathbf{2 7 5 . 9 8} \pm \mathbf{1 5 8 . 0 4}$ & $\mathbf{1 9 2 . 9 8} \pm \mathbf{8 7 . 2 *}$ \\
Leucine & $129.29 \pm 67.22$ & $141.63 \pm 74.78$ \\
Lysine & $346.46 \pm 230.63$ & $439.26 \pm 175.31$ \\
Ornithine & $160.47 \pm 70.78$ & $158.48 \pm 76.57$ \\
Phenylalanine & $341.39 \pm 307.22$ & $349.37 \pm 116.97$ \\
Phosphoserine & $\mathbf{0 . 7 6} \pm \mathbf{1 . 0 0}$ & $\mathbf{2 . 1 0} \pm \mathbf{1 . 8 3 ^ { * }}$ \\
Proline & $59.57 \pm 82.93$ & $48.26 \pm 55.12$ \\
Serine & $\mathbf{1 1 9 . 2 5} \pm \mathbf{4 0 . 7 7}$ & $\mathbf{1 5 1 . 2 7} \pm \mathbf{4 3 . 8 8 ^ { * }}$ \\
Taurine & $\mathbf{5 5 . 5 0} \pm \mathbf{9 . 6 1}$ & $\mathbf{2 6 . 3 4} \pm \mathbf{3 . 3 1}$ \\
Threonine & $273.53 \pm 118.31$ & $256.52 \pm 119.89$ \\
Tryptophan & $102.87 \pm 48.04$ & $82.08 \pm 30.73$ \\
Valine & $199.48 \pm 109.88$ & $231.12 \pm 83.33$ \\
\hline & &
\end{tabular}

Data are reported as means $\pm S D$ in $\mu \mathrm{m} .{ }^{*} \mathrm{P}<0.05$ for the non-immune hydrops fetalis group compared to control (Student $t$-test).

Table 3. Logistic regression model for levels of significant amniotic fluid amino acid levels.

\begin{tabular}{lcccccc}
\hline & $\beta$ & SE & Wald & Odds ratio & $95 \% \mathrm{Cl}$ & $\mathrm{P}$ \\
\hline Phosphoserine & 1.2 & 0.30 & 16.1 & 3.31 & $1.84-5.97$ & $<0.001$ \\
Taurine & 0.9 & 0.23 & 15.31 & 2.45 & $1.56-3.86$ & $<0.001$ \\
$\mathrm{NH}_{4}$ & 0.8 & 0.19 & 21.45 & 2.41 & $1.66-3.49$ & $<0.001$ \\
Arginine & 0.7 & 0.17 & 21.05 & 2.18 & $1.56-3.04$ & $<0.001$ \\
a-amino adipic acid & 0.5 & 0.21 & 7.62 & 1.78 & $1.18-2.68$ & $<0.001$ \\
\hline
\end{tabular}


samples (13). In our study, the phosphoserine and serine levels were lower, and taurine, aaa, glycine, cysteine, $\mathrm{NH}_{4}$, and arginine were higher in the NIHF group. Our conflicting findings suggest that further investigations should examine NIHF and amniotic fluid amino acid levels. To our knowledge, this was the first reported study to evaluate amniotic fluid amino acid levels in NIHF fetuses.

Using two experimental mouse models with intrauterine growth restriction (IUGR), Bhasin et al. (14) found reduced concentrations of essential amino acids. In previous studies, amino acid uptake had been found to be decreased in fetuses with IUGR, and this pathology was associated with a shift in the amino acid transport capacity and metabolic pathways within the fetoplacental unit $(15,16)$. In our study, we could not detect IUGR in the NIHF group because labor was induced with the approval of the families. In an experi-

\section{References}

1. Henrich W, Heeger J, Schmider A, Dudenhausen JW. Complete spontaneous resolution of severe nonimmunological hydrops fetalis with unknown etiology in the second trimester - a case report. J Perinat Med 2002; 30: 522-527.

2. McGillivray BC, Hall JG. Nonimmune hydrops fetalis. Pediatr Rev 1987; 9: 197-202.

3. Andersen HM, Drew JH, Beischer NA, Hutchison AA, Fortune DW. Non-immune hydrops fetalis: changing contribution to perinatal mortality. Br J Obstet Gynaecol 1983; 90: 636-639.

4. Wy CA, Sajous CH, Loberiza F, Weiss MG. Outcome of infants with a diagnosis of hydrops fetalis in the 1990s. Am J Perinatol 1999; 16: 561-567.

5. Czernik C, Proquitte H, Metze B, Buhrer C. Hydrops fetalis - has there been a change in diagnostic spectrum and mortality? J Matern Fetal Neonatal Med 2011; 24: 258-263.

6. lijima S, Ohzeki T. A case of nonimmune hydrops fetalis that was successfully treated with ulinastatin. Paediatr Perinat Drug Ther 2005; 6: 193-196.

7. Bellini C, Hennekam RC, Fulcheri E, Rutigliani M, Morcaldi $\mathrm{G}$, Boccardo F, et al. Etiology of nonimmune hydrops fetalis: a systematic review. Am J Med Genet A 2009; 149A: 844851.

8. Celik Y. Biostatistics, principles of research. Diyarbakir: Dicle University Press; 2007.

9. Harahan D, Murphy JF, O'Brien N, Gorman W, Kelehan $\mathrm{P}$, Cullinane $\mathrm{C}$, et al. Clinico-pathological findings in nonimmune hydrops fetalis. Ir Med J 1991; 84: 62-63. mental rat model, Gurekian and Koski (17) found that the amniotic fluid amino acid concentrations can be modified by the dietary intake and body mass index (BMI) of the mother. We did not evaluate the BMI or dietary habits of the mothers and we think that this is one limitation of our study.

In conclusion, to our knowledge, this is the first study reported to investigate the amniotic fluid amino acid concentrations in fetuses with NIHF. The odds ratios of the amino acids and significantly different levels of some amino acids may be diagnostic factors for NIHF.

\section{Acknowledgments}

We thank Prof. Dr. Ibrahim Tunik and www.textcheck. com/certificate/LTVIFw for English revision.

10. Poeschmann RP, Verheijen RH, Van Dongen PW. Differential diagnosis and causes of nonimmunological hydrops fetalis: a review. Obstet Gynecol Surv 1991; 46: 223-231.

11. Mascaretti RS, Falcao MC, Silva AM, Vaz FA, Leone CR. Characterization of newborns with nonimmune hydrops fetalis admitted to a neonatal intensive care unit. Rev Hosp Clin Fac Med São Paulo 2003; 58: 125-132.

12. Queenan JT. Amniotic fluid proteins, amniotic fluid amino acids and their clinical significance. In: Fairweather DVI, Eskes TKAB (Editors), Amniotic fluid: research and clinical application. 2nd edn. Amsterdam: Excerpta Medica; 1978. p 187-208.

13. Jauniaux E, Gulbis B, Gerlo E, Rodeck C. Free amino acid distribution inside the first trimester human gestational sac. Early Hum Dev 1998; 51: 159-169.

14. Bhasin KK, van Nas A, Martin LJ, Davis RC, Devaskar SU, Lusis AJ. Maternal low-protein diet or hypercholesterolemia reduces circulating essential amino acids and leads to intrauterine growth restriction. Diabetes 2009; 58: 559-566.

15. Harding J. Nutritional causes of impaired fetal growth and their treatment. J R Soc Med 1999; 92: 612-615.

16. Regnault TR, Friedman JE, Wilkening RB, Anthony RV, Hay WW Jr. Fetoplacental transport and utilization of amino acids in IUGR - a review. Placenta 2005; 26 (Suppl A): S52-S62.

17. Gurekian CN, Koski KG. Amniotic fluid amino acid concentrations are modified by maternal dietary glucose, gestational age, and fetal growth in rats. J Nutr 2005; 135: 2219-2224. 